guidelines by middle-aged adults with current asthma. Thorax 2009;64:1025-31.

5. Woolcock A, Rubinfeld AR, Seale JP, et al. Thoracic Society of Australia and New Zealand Asthma Management Plan 1989. Med J Aust 1989;151: 650-3.

6. Adams S, Pill R, Jones A. Medication, chronic illness and identity: the perspective of people with asthma. Soc Sci Med 1997;45:189-201.

7. Dekker FW, Dieleman FE, Kaptein AA, et al. Compliance with pulmonary medication in general practice. Eur Respir J 1993;6:886-90.

8. Steven K, Morrison J, Drummond N. Lay versus professional motivation for asthma treatment: a cross-sectional, qualitative study in a single Glasgow general practice. Fam Pract 2002;19:172-7.

9. Adams RJ, Wilson D, Smith BJ, et al. Impact of coping and socioeconomic factors on quality of life in adults with asthma. Respirology 2004;9: 87-95.
10. McGann EF, Sexton D, Chyun DA. Denial and compliance in adults with asthma. Clin Nurs Res 2008;17:151-70.

11. Rhee H, Belyea MJ, Ciurzynski S, et al. Barriers to asthma self-management in adolescents: relationships to psychosocial factors. Pediatr Pulmonol 2009;44:183-91.

12. Adams RJ, Appleton SL, Hill CL, et al. Inadequate health literacy is associated with increased asthma morbidity in a population sample. J Allergy Clin Immunol 2009. doi:10.1016/j.jaci.2009.05.035

13. Partridge MR. Living with a variable disease. Pulm Pharmacol Ther 2002:15:491-6.

14. Horne R, Price D, Cleland J, et al. Can asthma control be improved by understanding the patient's perspective? BMC Pulm Med 2007;7:8.

15. Global Initiative for Asthma (GINA). Global strategy for asthma management and prevention. Updated 2008. www.ginasthma.org (accessed 17 Aug 2009).
16. Charlton I, Charlton GF. Caring for patients with asthma. Teaching self management takes time. BMJ 1994;308:1370-1.

17. Saini B, Krass I, Armour C. Development, implementation, and evaluation of a community pharmacy-based asthma care model. Ann Pharmacother 2004;38:1954-60.

18. Charlton I, Charlton G, Broomfield J, et al. Audit of the effect of a nurse run asthma clinic on workload and patient morbidity in a general practice. $\mathrm{Br} \mathrm{J}$ Gen Pract 1991;41:227-31.

19. Smith JR, Mildenhall S, Noble MJ, et al. The Coping with Asthma Study: a randomised controlled trial of a home based, nurse led psychoeducational intervention for adults at risk of adverse asthma outcomes. Thorax 2005;60:1003-11.

20. Australian Government Medicare Australia Practice Incentives Program (PIP) - Asthma Incentive. http://www.medicareaustralia.gov.au/provider/ incentives/pip/payment-formula/asthma-incentive.jsp (accessed 19 Aug 2009)

\title{
Asthma: what's the bleeding point?
}

\section{Simon C Pitchford, ${ }^{1}$ James D Moffatt ${ }^{2}$}

Inflammation and coagulation are complex biological pathways that interact with each other in a variety of chronic diseases. Although they are often considered to be distinct processes, it is almost impossible to dissect the one from the other, except at their functional extremes. ${ }^{1}$ Activation of the coagulation cascade appears to be common to diverse inflammatory lung diseases such as acute lung injury, idiopathic lung fibrosis, acute respiratory distress syndrome and sarcoidosis. ${ }^{2}$ It is no great surprise, then, to find evidence of activation of the coagulation cascade in a chronic inflammatory disease such as asthma. Indeed, several studies over the last 10 years or so have consistently found markers for coagulation in the airways of subjects with asthma. ${ }^{3-7}$ However, taking an informative snapshot of all the relevant team members in coagulation and inflammation in such a setting is a bit like taking a photograph of a 10-car pile-up on a motorway. Such pictures could generate widespread speculation as to the true course of events that led to the disaster. A comprehensive exploration of the presence of various

\footnotetext{
${ }^{1}$ Leukocyte Biology Section, National Heart and Lung Institute, Imperial College London, London, UK; ${ }^{2}$ Division of Basic Medical Sciences, St George's, University of London, London, UK

Correspondence to: Dr Simon Pitchford, Leukocyte Biology Section, National Heart and Lung Institute, Imperial College London, 3rd Floor, Sir Alexander Fleming Building, Exhibition Rd, London SW7 2AZ, UK; s.pitchford@imperial.ac.uk
}

factors governing the balance between coagulation and fibrinolysis, and their relationship to asthma severity has been lacking. In this issue of Thorax, Brims et al (see page 1037) provide a new, more complete montage of the potential family members of the coagulation cascade present in the asthmatic airway. ${ }^{8}$ What can we learn from it, and what future work would help us see how inflammatory pileups may be modulated or prevented?

Although glucocorticosteroids are the mainstay of asthma treatment, many of the structural changes that occur in the airways appear to be steroid resistant. ${ }^{9}{ }^{10}$ It is likely, therefore, that some remodelling processes occur independently of inflammation. In subjects with severe asthma, Brims et al reveal that procoagulant factors which might contribute to airway remodelling (see below) persist at elevated levels despite glucocorticosteroid therapy, ${ }^{8}$ and are independent of inflammatory cell influx. ${ }^{8}$ These extrinsic procoagulant factors are probably produced by a local cellular source (eg, epithelium, macrophages or fibroblasts) rather than from circulating cells. ${ }^{11}{ }^{12}$ Additionally, there is increasing evidence of platelet activation in patients with asthma. ${ }^{13}$ Platelets have also been observed to penetrate through lung interstitial tissue directly in response to allergen and locate to the airway wall. ${ }^{14}$ Because they lack a nucleus, platelets are one of the few cells in the body that are unaffected by glucocorticosteroids.
Further, platelet depletion resulted in the virtual abolition of remodelling events in a murine model of chronic allergic inflammation, whereas some remodelling events (including subepithelial fibrosis and collagen deposition) persisted after continuous administration of a glucocorticosteroid (dexamethasone). ${ }^{15}$ Extravascular platelets may therefore also provide a potent stimulatory platform for coagulatory events leading to airway remodelling in the lungs of subjects with asthma that is steroid resistant.

How would mediators of the coagulation/fibrinolytic processes affect the lung? Brims et al suggest that in subjects with moderate asthma there may be a fibrinolytic environment that encourages destruction of the extracellular matrix (ECM) via enhanced plasmin production (eg, through increased tissue plasminogen activator (tPA) and urokinase plasminogen activator ( $\mathrm{UPA}$ ) release, inhibition of plasminogen activator inhibitor-1 (PAI-1) or activation of protein $C$ ) ensuring the removal of glycoproteins and activation of matrix metalloproteinases (MMPs). ${ }^{8}$ It has been hypothesised that inappropriate activation of this plasmin system would accelerate the production of inflammatory mediators and growth factors that influence processes such as collagen deposition and airway smooth muscle (ASM) proliferation. ${ }^{16}$ However, it is difficult to envisage this fibrinolytic scenario occurring in the lungs purely on the evidence gained with this clinical study. Alternatively, the profibrinogenic/antifibrinolytic environment reported here in subjects with severe asthma and also in those with moderate asthma directly after allergen exposure might affect lung function via fibrin deposition or via a soup of coagulation factors involved in remodelling. ${ }^{3} 51718$ 
Indeed, evidence for fibrin deposition has been reported along the luminal surface of distal airways in a patient who died of status asthmaticus and also in experiments using mice subjected to allergic airway inflammation. ${ }^{3}$ Experimentally, lung fibrinolysis via the installation of tPA reversed the increase in airways hyper-responsiveness (AHR) in allergenchallenged mice. ${ }^{3}$ Further, allergeninduced AHR could be mimicked in separate experiments where mice were exposed to nebulised fibrin. ${ }^{3}$ The significance of fibrin deposition in the airways is that it may induce airway closure, leading to an increase in peripheral resistance, a situation that may be confounded by the ability of fibrin to inactivate surfactant. ${ }^{3}$ However, it has been suggested that the effects of fibrin deposition are probably not confined to airway closure but that factors of the coagulation cascade most probably also contribute to other remodelling phenomena that increase AHR. ${ }^{17}$

Interest in the interplay between coagulation and inflammation in inflammatory diseases gained some respectability after the cloning of a family of $G$ proteincoupled receptors that mediate some of the effects of various coagulation factors on cells. These proteinase-activated receptors (PARs) may account for the biological actions of thrombin, factor $\mathrm{Xa}$ (FXa), FVIIa, activated protein C, as well as other endogenous and exogenous proteinases. PARs are expressed by most of the "interesting" cells in the airways, such as smooth myocytes, fibroblasts, epithelia at all levels of the airways and inflammatory cells. Activation of PARs on such cells in vitro has generally been shown to exert effects consistent with a role for PARs in disease progression in inflammatory airway diseases. One of the most obvious and consistent findings of Brims et al is that the notable triad of tissue factor (TF), FVII and FX is absent in samples of induced sputum from subjects with severe asthma. ${ }^{8}$ Since an index of plasma exudation ( $\alpha_{2}$-macroglobulin) suggests that these factors should be present in the "inflammatory soup" in proportion to other plasma proteins in these patients, one obvious suggestion is that the ternary TF-FVII-FX complex is bound to cells in the lung, and cannot be retrieved from the airways by this sampling technique. If indeed the TF-FVIIFX complex is bound to local airway cells, then perhaps it is signalling via PAR1/PAR2 and acting as a profibrotic stimulus, as proposed recently in lung fibrosis. ${ }^{12} 18$ The absence of TF, FVII and FX in the most severe patients, where many would argue that airway remodelling would be pronounced, is compelling.

Thrombin has been known to cause smooth muscle and fibroblast proliferation for many years; these effects relevant to airway wall remodelling may or may not be PAR dependent. ${ }^{19}$ Thrombin has also been suggested to contract ASM and induce inflammatory cytokine expression by airway cells. ${ }^{19}$ However, detecting active thrombin in the asthmatic airway appears to be a hit and miss affair. Brims et al found an insignificant trend for increasing thrombin levels with increasing disease severity. ${ }^{8}$ Some previous studies have found clear evidence of active thrombin in the airways, either directly or in the form of thrombinantithrombin (TAT) complexes. ${ }^{520}$ A very recent study detected active thrombin following allergen challenge, suggesting that the timing of sampling may be an important factor. ${ }^{5}$ It is also possible that the airways of those with severe asthma-where evidence of baseline plasma exudation is clearest-have an increased capacity to buffer active thrombin by the production of antithrombin and similar molecules. Given the degree of speculation about the contribution of thrombin to the development of asthma, studies of how thrombin activity is regulated in the airways in health and disease are warranted.

The data presented by Brims et al are not easy to come by. Studies of this kind require a coordinated research effort that was previously lacking in the literature. It is a rare privilege to see the snapshot that has been taken for us. To our knowledge, no single study of an animal model has presented similar data. This seems disappointing, in light of the many studies that have shown that manipulation of the coagulation cascade can ameliorate signs of allergic airway disease in animal models. An equally thorough appraisal of the various animal models is warranted if we are to continue to rely on them for insights into respiratory diseases, especially since there is an extensive library of "off-the-shelf" anticoagulant drugs whose actions may affect lung remodelling and are therefore worthy of further endeavour.

\section{Competing interests: None.}

Provenance and peer review: Commissioned; not externally peer reviewed.

Thorax 2009;64:1014-1015.

doi:10.1136/thx.2009.120279

\section{REFERENCES}

1. Delvaeye M, Conway EM. Coagulation and innate immune responses: can we view them separately? Blood 2009;114:2367-74.

2. Chambers RC. Procoagulant signalling mechanisms in lung inflammation and fibrosis: novel opportunities for pharmacological intervention? Br J Pharmacol 2008;153(Suppl 1):S367-78.

3. Wagers SS, Norton RJ, Rinaldi LM, et al. Extravascular fibrin, plasminogen activator, plasminogen activator inhibitors, and airway hyperresponsiveness. J Clin Invest 2004;114:104-11.

4. Bowen RM, Hoidal JR, Estensen RD. Urokinase-type plasminogen activator in alveolar macrophages and bronchoalveolar lavage fluid from normal and smokeexposed hamsters and humans. J Lab Clin Med 1985; 106:667-73.

5. Schouten M, Van de Pol MA, Levi M, et al. Early activation of coagulation after allergen challenge in patients with allergic asthma. J Thromb Haemost 2009; 7:1592-4.

6. Terada M, Kelly EAB, Jarjour NN. Increased thrombin activity after allergen challenge. Am J Respir Crit Care Med 2004;169:373-7.

7. Gabazza EC, Taguchi 0, Tamaki S, et al. Thrombin in the airways of asthmatic patients. Lung 1999;177:253-62.

8. Brims FJ, Chauhan AJ, Higgins B, et al. Coagulation factors in the airways in moderate and servere asthma and the effect of inhaled steroids. Thorax 2009;64:1037-43.

9. Boulet LP, Turcotte $H$, Laviolette M, et al. Airway hyperresponsiveness, inflammation, and sub-epithelial collagen deposition in recently diagnosed versus long standing mild asthma: influence of inhaled corticosteroids. Am J Resp Crit Care Med 2000;162:1308-13.

10. Lundgren $\mathbf{R}$, Soderberg $M$, Horstedt $P$, et al. Morphological studies of bronchial mucosal biopsies from asthmatics before and after ten years of treatment with inhaled steroids. Eur Respir $J$ 1988; 1:883-9.

11. Perrio MJ, Ewen D, Trevethick MA, et al. Fibrin formation by wounded bronchial epithelial cell layers in vitro is essential for normal epithelial repair and independent of plasma proteins. Clin Exp Allergy 2007:37:1688-700.

12. Scotton CJ, Krupiczojc MA, Konigshoff $M$, et al. Increased local expression of coagulation factor $X$ contributes to the fibrotic response in human and murine lung injury. J Clin Invest 2009;119: 2550-63.

13. Kowal K, Pampuch A, Kowal-Bielecka 0, et al. Platelet activation in allergic patients during allergen challenge with Dermatophagoides pteronyssinus. Clin Exp Allergy 2006;36:426-32.

14. Pitchford SC, Momi S, Baglioni S, et al. Allergen induces the migration of platelets to lung tissue in allergic asthma. Am J Resp Crit Care Med 2008;177:604-12.

15. Pitchford SC, Riffo-Vasquez $Y$, Sousa A, et al. Platelets are necessary for airway wall remodelling in a murine model of chronic allergic inflammation. Blood 2004;103:639-47.

16. Kucharewicz I, Kowal K, Buczko W, et al. The plasmin system in airway remodelling. Thromb Res 2003:112:1-7.

17. Matthay MA, Clements JA. Coagulation-dependent mechanisms and asthma. J Clin Invest 2004;114:20-3.

18. Shinagawa K, Martin JA, Ploplis VA, et al. Coagulation factor $X a$ modulates airway remodeling in a murine model of asthma. Am J Resp Crit Care Med 2007;175:136-43.

19. Moffatt JD, Page CP, Laurent GJ. Shooting for PARs in lung diseases. Curr Opin Pharmacol 2004; 4:221-9.

20. Terada $\mathbf{M}$, Kelly EAB, Jarjour NN. Increased thrombin activity after allergen challenge. Am J Respir Crit Care Med 2004;169:373-7. 